\title{
EL CD-ROM EN ESPAÑA: \\ LUCES Y SOMBRAS DE NUEVE AÑOS DE PRODUCCION
}

\author{
Pedro Hípola y Félix de Moya*
}

Resumen: La edición de discos ópticos en España comienza el año 1985. Desde entonces hasta ahora la producción de CD-ROMs que contienen información generada en nuestro país ha experimentado un notable crecimiento. En estos años de evolución se han producido importantes aciertos y fracasos. A continuación se analiza la historia, situación actual y perspectivas de futuro del sector de la edición de CD-ROMs en España.

Palabras clave: Edición de CD-ROM, España.

\begin{abstract}
Optical disc production in Spain began in 1985. Since then, the production of CD-ROMs containing information generated in our country has experienced a remarkable growth. During these years of development important successes and failures have occurred. In the following pages the history, present situation and future prospects of the CD-ROM production sector are examined.
\end{abstract}

Keywords: CD-ROM edition, Spain.

\section{Introducción}

Redactar unos apuntes históricos sobre la edición del CD-ROM en España es sin duda una tarea delicada. Ahora sólo es posible esbozar los primeros párrafos de un capitulo inacabado. Apenas han empezado a publicarse discos, y la producción promete ser muy prolífica durante los próximos años. Por eso intentar valorar acontecimientos recientes de una historia que está tan viva puede resultar arriesgado. La falta de perspectiva fácilmente induce a extraer conclusiones injustas.

Por otra parte, el análisis de los hechos que aquí van a ser comentados debería ser encuadrado dentro de un relato más amplio sobre la evolución de la industria de la información electrónica en nuestro país. Es evidente que las condiciones en que se encontraba la oferta de bases de datos españolas a mediados de los ochenta ha condicionado en gran medida la forma en la que se ha desenvuelto el mercado de la edición del CD-ROM.

En las siguientes páginas, no obstante, trataremos de ofrecer un sucinto guión sobre la producción de discos con información generada en España, procurando destacar lo que a nuestro juicio constituye los principales aciertos y fracasos que se pueden observar en estos nueve años.

Nuestros comentarios se centrarán principalmente en los productos que se han publicado hasta ahora y en las políticas de edición que pueden observarse en las principales empresas e instituciones españolas involucradas en el proceso de edición de CD-ROMs. Es posible que el lector pueda detectar omisiones o algún dato

* E.U. de Biblioteconomía y Documentación, Universidad de Granada.

Recibido 20-8-93. 
incorrecto. Aunque hemos tratado de documentar suficientemente nuestro trabajo, pedimos disculpas de antemano por los posibles errores.

Pensamos que estos nueve años de producción pueden agruparse en tres etapas:

1. Los inicios del CD-ROM español (1985-1989).

2. Un mercado que no se define (1990-1991).

3. Explosión (1991-1993).

Como es lógico, las fases de esta evolución no se corresponden exactamente con la secuencia cronológica de los años naturales. Así, por ejemplo, el mercado experimenta una importante metamorfosis en la segunda mitad del año 1991. Es por esto que tal año se encuentra incluido tanto en la etapa segunda como en la tercera.

\section{Los inicios del CD-ROM español (1985-1989)}

La historia de la edición del CD-ROM en España tiene un comienzo prematuro. Poco tiempo después de que fueran definidas a nivel internacional las primeras especificaciones técnicas que regularian el uso de este soporte, una compañía barcelonesa se lanza a explotar la nueva tecnología. Sus actividades comienzan ya en 1985.

La Editorial Marín crea una firma subsidiaria, Comunicación y Cálculo (Comcal), que se encargará de analizar las prestaciones de estos discos, con el objetivo de actuar como una «imprenta de CD-ROMs» para editores de obras de referencia.

Contando con el apoyo de The Lagrange Group, Comcal pone a punto dos de los primeros títulos CD-ROM que aparecen a nivel mundial. En uno se publica el Diccionario de Medicina Marín. El otro contiene la base de datos del Vademécum Español de Especialidades Farmacéuticas en formato dBase, un diccionario inglés y una librería de imágenes.

Hay que destacar el espíritu innovador del proyecto, algo no siempre presente en el sector editorial español. El equipo de trabajo apenas disponía de bibliografia técnica para abordar el proyecto y tuvo que realizar un gran esfuerzo de desarrollo, pues no se vio conveniente, por motivos económicos, utilizar licencias de explotación de software de terceros. La aplicación que se preparó para gestionar la base de datos documental se denominó LST.

Hoy parece evidente que el año 1986 no era todavía el momento más idóneo para introducir en el mercado español un producto CD-ROM, aunque fuera una aplicación vertical dirigida al mundo médico, colectivo que tradicionalmente ha asimilado con gran rapidez las innovaciones tecnológicas para la recuperación de información. El número de ordenadores personales en España era aún muy reducido, entre otras cosas por el fuerte contraste entre prestaciones y precios de los microordenadores que entonces se estaban importando. Y por supuesto, los lectores de CD-ROMs iban a tardar todavía mucho en ser conocidos por un número suficiente de personas dentro de nuestro país.

En consecuencia, aunque se realizaron notables esfuerzos para comercializar el nuevo sistema de edición electrónica, no puede decirse que encontrara gran aceptación. Y la Editorial Marín tuvo entonces que dar por cerrada esta aventura tecnológica, la primera avanzadilla de edición en soporte óptico que se realizó en 
España. La empresa, sin embargo, no descarta la posibilidad de publicar en el futuro una nueva edición del Diccionario Médico en CD-ROM.

El siguiente episodio de nuestra historia es la participación de Ediciones Anaya en la preparación del CD-ROM con el Diccionario Multilingüe Harrap's. Se trata de un interesante producto, editado en Japón, que incluye dieciocho diccionarios en doce lenguas, gestionados por un software que interrelaciona todos los diccionarios y que puede funcionar en modo residente, conviviendo pacíficamente con los principales procesadores de textos del mercado. Anaya aporta los contenidos del diccionario Vox español-inglés, inglés-español.

La empresa decide entonces dedicarse a la edición de productos CD-ROM y adquiere una máquina de premastering. El proyecto editorial aparece reseñado incluso en alguna publicación internacional especializada en temas de la profesión. Pero la realidad es que hasta el día de hoy no ha aparecido en el mercado ningún producto preparado por Anaya en ese equipo informático. Es más, la máquina fue recomprada unos años más tarde por la empresa Micronet.

En algunas ocasiones se ha dicho que el diccionario Harrap's fue el primer CD-ROM publicado en España. Es evidente, por lo que ya hemos relatado antes, que no es el primero. Además, aunque contiene una valiosa información producida en España, no se puede decir que el disco en sí sea un producto español. En cualquier caso, se trata de una útil herramienta de trabajo.

Poco tiempo después tenemos la entrada en escena de una tercera empresa del mundo editorial: Distribuciones La Ley. En este caso se trata de una compañía, relacionada al principio con su casa matriz en Argentina, que era suficientemente prestigiosa en nuestro país por los productos impresos con información jurídica española que publicaba. La Ley había organizado una división que se dedicaba a realizar desarrollos informáticos. Esta división pone a punto la primera versión del software utilizado en la serie de productos Compuley.

El equipo de programadores preparó una aplicación en Cobol, con la siguiente filosofia: los usuarios de los nuevos discos usarán los índices del CD-ROM de la misma manera en que se realiza una búsqueda manual con los productos impresos de La Ley. Esta concepción, que resultó útil para que los primeros usuarios aceptaran y asimilaran rápidamente el manejo de la nueva herramienta, desembocó en un rígido sistema de menús que a la larga se reveló como inaceptable.

De todas maneras, una buena campaña de marketing, acompañada sobre todo por un sistema de soporte posventa eficaz, produjo como resultado un número de clientes nada despreciable. Los discos de Compuley fueron los primeros CD-ROMs españoles que se introdujeron con cierto éxito en el mercado nacional.

De forma paralela a estos acontecimientos, varias - pocas - empresas españolas habían contactado coh el mundo del CD-ROM por el camino de la distribución. A la cabeza de ellas se encontraba Micronet. La compañía había tenido un fuerte crecimiento a lo largo de la década de los ochenta actuando como mayorista de software importado para microordenadores. Así mismo, siempre contó con un departamento dedicado a hacer desarrollos informáticos propios. Entre los productos que entonces produce se encuentra un gestor de bases de datos documentales, denominado Docutex, cuya evolución dará lugar después al conocido software Knosys.

Micronet, como hemos dicho, estaba a la cabeza de la distribución en España de los CD-ROMs producidos en otros países. Así, por ejemplo, hasta 1989 la 
empresa fue suministradora en exclusiva de los discos de Silverplatter, el gran editor norteamericano. El conocimiento que llegaron a adquirir sobre este mercado les animó a preparar una versión de su base de datos documental que fuera capaz de gestionar información almacenada en discos CD-ROM. Así surge CD-Knosys, producto con el que Micronet llegará a convertirse en el principal editor de CD-ROMs del país.

Con Micronet se produce, por primera vez en España, una serie de fenómenos reseñables. Por una parte, la labor de preparación del producto final la llevará a cabo en esta ocasión una empresa informática, no una editorial. Además se trata de un editor electrónico que va a publicar bases de datos generadas por terceros. Hasta entonces sólo contábamos con productores-editores - lo cual nos recuerda, por cierto, una de las tendencias de nuestro mercado en línea--. Desde este momento los editores de CD-ROMs españoles van a ser prácticamente siempre organizaciones diferentes de los productores de la información. $Y$ nos encontramos, por otra parte, con que una empresa española produce un software que puede gestionar CD-ROMs con bases de datos muy variadas. Es decir, no es un programa "ad hoc», que es lo que se habia visto hasta ese momento en los anteriores discos.

Con CD-Knosys se publican en primer lugar los índices de legislación Aranzadi, un producto que le hará la competencia a Compuley, y que la editorial navarra consigue distribuir con bastante éxito. Micronet también edita la base de datos de la agencia española del ISBN. Por su indudable interés, especialmente para el sector de las librerias, se trata de uno de los CD-ROMs españoles que más se ha vendido, si bien ha de tenerse en cuenta que desde sus comienzos el producto fue subvencionado por el Ministerio de Cultura.

Algunas personas, especialmente del mundo de las bibliotecas, han criticado el contenido de esta base de datos, que evidentemente carece de prestaciones existentes en otros productos similares, como los Books in Print de diversos países. Por otra parte, realizar búsquedas por temas en este disco resulta frustrante. Pero también es verdad que el colectivo bibliotecario, tan retrasado en labores de automatización, no tenía por esos años en nuestro país grandes ofertas para ofrecer como alternativas al nuevo CD-ROM.

Otro producto importante editado con CD-Knosys fue el disco con las bases de datos del Consejo Superior de Investigaciones Cientificas (CSIC). Muchas personas pudieron descubrir entonces que el tamaño de los Indices de Ciencia y Tecnología y Humanidades correspondientes a la producción científica española no era tan grande como esperaban. En el disco fueron incluidos también todos los registros de los catálogos colectivos de la red de bibliotecas del Consejo. Un producto, en definitiva, imprescindible, que, junto con los otros dos citados, sirvió para lanzar a Micronet al puesto de principal editor de CD-ROMs en España.

Así terminaba el año 1989. Y todo parecía augurar un fuerte despegue en la producción de CD-ROMs españoles.

\section{Un mercado que no se define (1990-1991)}

El despegue, sin embargo, no se acaba de producir en el siguiente año. Los títulos que ya se habían comenzado a publicar continúan reeditándose durante 
1990 en forma de sucesivas actualizaciones. Pero no parece llegar la explosión de nuevos títulos esperada.

El problema es que en España no había grandes bases de datos, y quien tenía ficheros publicables no se animaba a ponerlos en «las manos» de los usuarios. Es llamativo, en este orden de cosas, ver que la mayoría de los CD-ROMs que se han publicado en nuestro país contiene bases de datos de un volumen no muy extenso. Algunos discos tienen libre gran cantidad del espacio disponible. Los ficheros que en ellos se incluyen muy bien podrían haberse distribuido en un conjunto de disquetes, para ser instalados sin más dentro del disco duro.

Además en 1990 se van a publicar varios productos con «techo bajo». Este es, a nuestro juicio, el caso de La Luz. Cuando presenta este título al mercado, Micronet demuestra que continúa en la línea de la innovación tecnológica. La evolución de Knosys proseguía, y se estaba distribuyendo una nueva versión del software, capaz de presentar imágenes en pantalla. El desarrollo, conocido comercialmente como Clarity, sirvió de base para editar en CD-ROM un catálogo del Barcelona Centre de Disseny, en el que se incluía la imagen digitalizada a todo color de una buena colección de lámparas. Erà la primera base de datos con imágenes que aquí se editaba, pero indudablemente se trataba de un CD-ROM que no iba a ser utilizado por grandes cantidades de usuarios.

Por la misma época, poco después, aparece en España un nuevo editor de CD-ROMs, que se encarga de publicar un título muy similar a La Luz. Nos referimos a la Base de datos de diseño, una serie de discos promovida por el Ministerio de Industria. El proyecto original era preparar seis volúmenes. Multimicro Informática, una compañia de Benidorm, prepara la aplicación, denominada CD-Visión, con la que se edita el primero de los volúmenes, que contiene textos (en inglés y castellano) e imágenes en color de muebles y complementos del hogar. Se encarga del premastering La Ley. De nuevo nos encontramos con un proyecto de escasa acogida. No se ha vuelto a editar ninguno de los volúmenes restantes a pesar de que los correspondientes materiales fueron preparados.

Algo mayor fue la difusión de Documentación de Medios, que es también el primer producto en su género. A pesar de que España producía varias bases de datos con información de prensa diaria, y aunque Baratz llevaba cierto tiempo asegurando que se publicaría pronto un $\mathrm{CD}-\mathrm{ROM}$ con su fichero, la primera base de datos de prensa que aparece en disco es ésta. El software, CD-Knosys, de Micronet; el contenido, un número no muy abundante de registros que incluían información referencial sumaria de artículos seleccionados por la empresa Documentación de Medios. El CD-ROM no ha tenido la aceptación que productor $y$ editor esperaban.

Los siguientes meses se producen «turbulencias» en el sector español de la edición de CD-ROMs. Una buena cantidad de instituciones y empresas ha adquirido lectores de CD-ROM y se ha suscrito a diversos títulos, en su inmensa mayoría producidos fuera de España. El soporte óptico digital ya no es tan desconocido. Los usuarios están familiarizados con diferentes sistemas de recuperación. Son capaces de evaluar, comparar... y extraer conclusiones. Aquí comienza a quedar patente la calidad de los paquetes producidos por fuertes empresas norteamericanas, en contraste con los desarrollos que habían sido realizados en España disponiendo de menos recursos. 
La Ley no tiene más remedio que reconocer las limitaciones de su software. Y se ve obligada a sustituirlo por un paquete americano, el de Dataware, que ha llegado a ser el sistema de edición de CD-ROMs con el que más títulos son editados en todo el mundo. La serie Compuley continúa publicándose pagando ahora licencias de uso de software importado. Había comenzado lo que podríamos denominar el «desembarco» de Dataware, pues este sistema no sólo será utilizado por la editorial jurídica, sino que también van a obtener licencias de distribución del software dos empresas barcelonesas, DOC6 y la Editorial Prous. Será La Ley la primera empresa española que realice desarrollos utilizando las librerías de funciones de la versión para desarrolladores del sistema Dataware.

Con este sistema de origen americano La Ley ha ido aumentando el número de títulos de la serie Compuley, y además está llevando a cabo la edición de otros ficheros. El primero de ellos ha sido Cibepat, una base de datos de patentes producida por el entonces Registro de la Propiedad Industrial, hoy Oficina Española de Patentes y Marcas. La Ley empieza así a ser editora de productos de terceros.

Poco después se produce otro acontecimiento importante. El Consejo Superior de Investigaciones Científicas considera que Micronet no está realizando el suficiente esfuerzo de marketing para difundir sus bases de datos en disco. Además, se juzga que CD-Knosys no se adapta suficientemente a las necesidades y hábitos de los usuarios finales. Por estos motivos se decide hacer un contrato de edición de las bases de datos CSIC con otra empresa. Y se elige La Ley.

Micronet, sin embargo, continúa publicando los ficheros del Consejo con CDKnosys. El producto, a pesar de ser producido en tiradas no muy grandes, comienza entonces a distribuirse con dos sistemas distintos.

Pero no acaban aquí los tiempos de "turbulencias», pues también por esta época comienza el accidentado proceso de las bases de datos CD-ROM de ColexData. Quien editará estos importantes ficheros será Logitec, una empresa zaragozana que habia adquirido popularidad en el mundo de la documentación y las bibliotecas, pues estaba realizando una fuerte difusión de productos CD-ROM de importación, especialmente la base de datos Medline en la versión de Ebsco. Esta empresa informática también habia desarrollado un sistema de automatización de bibliotecas, Sgbc, que sin embargo nunca ha tenido gran aceptación.

Para editar el nuevo título, Logitec se encarga de-traducir al castellano otro software desarrollado en Estados Unidos, bastante extendido allí, que se comercializa con el nombre de Kaware. Varios factores producirán insatisfacción en el seno de la empresa productora de los registros jurídicos. Por una parte, las prestaciones del paquete informático no son muy avanzadas. Y, sobre todo, Colex-Data va a dar prioridad a un objetivo que considera crucial en su política de comercialización: el interface del disco CD-ROM ha de ser el mismo que el que la compañía utiliza como distribuidor online. De esta forma los usuarios no tendrán necesidad de aprender dos sistemas distintos de búsqueda. Sea por éstos o por otros motivos, Logitec dejará de ser el editor de las bases de datos CD-ROM de Colex-Data. Lo más propio era que el producto incorporara el software BRS/Search. Así se encargará de hacer la edición el Epi Centre británico, encomendándose la tarea de preparar el producto a la empresa distribuidora del paquete en España, Servicios de Teledocumentación.

Sin duda esta sucesión de vaivenes produce cierto desasosiego dentro del 
público que observa el desarrollo de la edición en discos ópticos que se estaba realizando en España. No parecía que el mercado despegara. Las cosas cambiarían con el «acelerón» que se produce a finales del año 1991.

\section{La explosion (1991-1993)}

El CD-ROM es un soporte con éxito asegurado en España, un país en el que nunca se ha desarrollado suficientemente la búsqueda en línea. En efecto, las empresas que se dedican a la importación de bases de datos en CD-ROM han ido aumentando en número y en volumen de facturación durante estos años. $Y$ a partir de 1991 crece considerablemente la cantidad de editores que se dedican a producir discos con información generada en España. Y también el número de productos: en menos de dos años se publican más de veinte nuevos títulos. Daremos cuenta de ellos sin seguir ya el orden cronológico, sino intentando agrupar los CD-ROMs según diversas categorías que nos permitan hacer breves comentarios.

Comienza a aparecer en los últimos dos años una serie de CD-ROMs con información española y que tienen su origen en proyectos internacionales, o al menos foráneos. Ciertamente no son productos cien por cien españoles, pero dado que están relacionados en mayor o menor medida con diversos ámbitos profesionales de nuestro país, hacemos una rápida mención de ellos. En este grupo podríamos incluir Urbamet, CD-Export, Hispanic Collection, Libros en venta en Hispanoamérica y España Plus, Ilolex y los discos de Disclosure y Dun \& Bradstreet.

Los dos primeros títulos citados incorporan bases de datos producidas por varios organismos europeos. El CD-ROM con información de urbanismo es editado por Questel y contiene Urbaterr, una base de datos referencial producida por el entonces denominado ISOC, organismo integrado ahora en el CINDOC.

CD-Export, disco producido por el Bureau Marcel Van Dijk, reúne, junto con otros ficheros, los datos aportados por el ICEX.

Por su parte, la red bibliotecaria americana OCLC (Online Computer Library Center) ha publicado un catálogo en CD-ROM, dentro de su serie Cat CD 450, denominado Hispanic Collection, en el que se incluyen un millón trescientas mil referencias en formato Marc, extraídas de su base de datos compartida, correspondientes a títulos en castellano, catalán, vasco y gallego.

Libros en venta en Hispanoamérica y España Plus es un disco de Bowker Electronic Publishing, que se corresponde con la séptima edición del producto preparado por el grupo editorial en soporte papel. Se distribuye con el software de Online Computer Systems. Contiene información bibliográfica de ciento cincuenta mil títulos en castellano.

Ilolex, con información suministrada por la International Labour Organization, ha sido editado por Kluwer Publishing Group. Incluye texto completo trilingüe (inglés, francés y español) sobre estándares relacionados con el trabajo.

Disclosure proporciona en una colección de discos las memorias anuales de las compañías que cotizan en los mercados de valores de una serie de países. Gracias a un acuerdo con la CNMV (Comisión Nacional del Mercado de Valores) desde 1993 están incluidas las memorias de las empresas que cotizan en las bolsas 
españolas. En el caso de la base de datos de Dun \& Bradstreet, que contiene información de treinta mil empresas españolas, estamos ante un título más de la serie de discos con directorios de compañías europeas que esta empresa está realizando como editor independiente durante los últimos meses (antes el editor de sus CD-ROMs era Lotus).

Con algunos de los productos «internacionales» se pueden observar nuevas oleadas de lo que hemos llamado el «desembarco» de Dataware, pues Questel en un principio editaba los discos con ese software. Y D\&B ha empezado a hacer uso de él desde hace unos meses.

1992 es para el mundo del CD-ROM español el año de las bibliotecas. Como se ha señalado antes, el disco del CSIC incorporaba desde el principio dos catálogos bibliotecarios. Ahora se van a publicar nuevos catálogos, pero esta vez en formato Marc. REBIUN, editado por DOC6, con información catalográfica procedente de un consorcio de bibliotecas universitarias, es no sólo el primer producto Marc del mercado CD-ROM español, sino también el primer disco en el que se utiliza el software estándar de Dataware para gestionar registros en formato Marc. No se puede considerar, de hecho, un catálogo colectivo, pues contiene registros duplicados, diferentes normas de descripción bibliográfica, variados sistemas de indización... El producto sirve sobre todo para facilitar el préstamo interbibliotecario.

Poco después se publica otro título procedente del mundo de las bibliotecas, quizá el más esperado, no sólo por el interés de los datos, sino también porque ya se habían oído promesas sobre su aparición durante años. Nos referimos a la Bibliografia Española, editada por Chadwick Healey con el software de Online Computer Systems. El triste episodio de las «eñes» sirvió para oscurecer en cierta medida el éxito de uno de los discos que se está vendiendo más en España y que tiene demanda fuera de las fronteras del Estado.

La delegación española de la empresa británica comienza además en 1992 a publicar una serie de productos agrupados bajo el nombre genérico de Bibliotecas sin fronteras. El primero de ellos es un catálogo colectivo, auspiciado por la Sociedad Estatal para el Quinto Centenario, con los fondos latinoamericanos existentes en seis importantes bibliotecas españolas. Para dentro de poco tiempo se anuncia la aparición de un catálogo colectivo de fondo antiguo generado por la Asociación de Bibliotecas Nacionales de Iberoamérica (ABINIA).

Pero el campo de producción española de CD-ROM más nutrido no es ni mucho menos el bibliotecario. Con mucha diferencia el sector jurídico es el que experimenta un mayor crecimiento en oferta de discos compactos. Hoy la serie Compuley no sólo incluye índices de jurisprudencia y de legislación, sino también textos completos de legislación laboral, civil, fiscal y administrativa. Se ha de destacar además que los cuatro últimos discos incorporan la versión hipertexto del software de Dataware, con lo que vemos aparecer en España los primeros productos que permiten hacer uso de esa técnica de recuperación.

Por su parte, Aranzadi ha añadido a su disco de legislación otro de jurisprudencia, editado ahora con una nueva versión del software de Micronet denominada CD-Knosys plus, que funciona en el entorno Windows. Desde el punto de vista técnico, la principal novedad del producto es que incorpora un programa que se encarga de la gestión de un tesauro preparado específicamente para esta base de datos. Un avance importante, cuyo uso podrá ser evaluado en los próximos meses. 
Con esa misma versión del software se editará la base de datos MAP-Lexter, producida por el Boletín Oficial del Estado y el Ministerio para las Administraciones Públicas, y compuesta por cuatro bases de datos, todas ellas en texto completo, con legislación estatal, autonómica, jurisprudencia y conflictos. Los textos van acompañados de descriptores.

Colex Data está ofreciendo referencias de jurisprudencia civil, constitucional, contencioso administrativa, laboral, penal, comunitaria, sobre derechos humanos, así como legislación en texto completo del $\mathrm{BOE}$, legislación y jurisprudencia fiscal y la base de datos del Colegio de Registradores de la Propiedad y Mercantiles.

Pero la oferta jurídica no acaba ahí. En estos años Micronet se ha encargado de editar Iberlex, la base de datos del BOE, así como el disco Lexco, con la información generada por La Ley de Argentina, empresa ahora desvinculada de la homónima española. Y anuncia otros dos productos del BOE: Lexter, una base sobre administraciones territoriales, y otra con legislación de las Comunidades Europeas. Logitec está editando las bases de datos de Lex Nova, con textos fiscales y laborales producidos por la editorial vallisoletana del mismo nombre. DOC6 ha preparado una tirada de discos con textos íntegros de disposiciones sobre Urbanismo de la Generalitat de Catalunya. Y Servicios de Teledocumentación ha editado en un CD-ROM, haciendo uso de BRS/Search - gestor de tesauros incluido-, Bases de datos documentales de la Dirección General de la Función Pública, perteneciente al Ministerio para las Administraciones Públicas.

Muchos piensan hoy que la oferta de información jurídica española en CDROM empieza a ser excesiva.

Las bases de datos de prensa, sin embargo, van mucho más retrasadas. Después de las sucesivas ediciones del ya citado fichero de Documentación de Medios, se publica por fin la base de datos Baratz, editada en CD-ROM por Servicios de Teledocumentación con el interfaz de recuperación BRS/Search. El fichero con referencias de prensa Baratz era ya veterano dentro del mercado español de la información electrónica, y la cantidad de sus registros supera con mucho a Documentación de Medios. Como es natural, también el precio es bastante superior.

Otro producto presentado hace muy poco es el de Microdoc. Ha sido preparado por la empresa zaragozana OCS y cuenta con la colaboración de Madrid Business School. Luego hablaremos más sobre este disco.

Pero sigue faltando en España la edición de un CD-ROM con textos íntegros de prensa escrita. Es de suponer que antes o después habrá algún periódico que se anime a ser el primero. Lo que sí acaba de aparecer es un disco con los textos e imágenes de cuatro años de la revista Anales de Pediatría, editada por la Asociación Española de Pediatría. La empresa que se ha encargado de la preparación y edición de la base de datos es CSi. Se trata del primer disco que se edita en España haciendo uso del software Windows Personal Librarian, uno de los más sofisticados gestores documentales que existen en el mercado.

Aranzadi-jurisprudencia y Anales de Pediatría, que aparecen a mediados de 1993, no son los primeros productos editados en nuestro país para el entorno Windows. Antes fueron publicados Admyte, Animales del Zoo, Juan Vives y su tiempo y Sinera. Y está anunciada una gran cantidad de títulos, la mayor parte de ellos destinada al gran público. Los títulos para el gran público merecerian ser analizados en un trabajo aparte. Aquí nos vamos a limitar a enumerar aquellos 
desarrollos de los que tenemos noticia, sin entrar en valoraciones, que consumirían gran cantidad de espacio. Tras la referencia a los productos Windows nos ocuparemos también de los CD-ROMs dirigidos al universo Macintosh.

Admyte es una colección de CD-ROMs destinada a un público especializado. El primer disco publicado incluye las imágenes digitalizadas de una colección amplia de manuscritos e incunables. El material gráfico se completa con esos mismos textos transliterados al alfabeto moderno y con una base de datos de lemas y formas. Un producto, en definitiva, concebido sobre todo para investigadores, fruto de un acuerdo entre la Sociedad Estatal para el Quinto Centenario, la Biblioteca Nacional y Micronet. El segundo volumen, denominado Admyte-0, contiene una colección de transcripciones de manuscritos españoles de los siglos XIII al XV.

Animales del Zoo es el primer título que publica BSI Multimedia, empresa de Barcelona cada vez más conocida en el sector informático por su importante presencia en la arena multimedia. Se trata de un CD-ROM que incorpora diversos materiales multimedia, incluyendo sonido e imágenes en movimiento. El premastering lo realiza CSi. Por fin tenemos un producto nacional compatible con la norma multimedia MPC. En la primera edición del disco se imprimió lo siguiente: «1er. CD-ROM fabricado en España».

Juan Vives y su tiempo es promovido por el Ayuntamiento de Valencia, con motivo del quinto centenario del nacimiento de este personaje. Contiene textos, imágenes y sonido sobre su historia. La aplicación la desarrolla la empresa valenciana Edicinco.

Sinera reúne una variada recopilación de materiales preparada por el PIE (Programa de Informática Educativa de la Generalitat de Catalunya): desde la base de datos bibliográfica Sinera hasta un diccionario multilingüe, pasando por una buena colección de software educativo y otras aplicaciones desarrolladas por el mismo PIE. Se trata así mismo de un producto multimedia, en el que no faltan imágenes animadas y sonidos.

En estos meses se están conociendo proyectos de nuevos títulos para el entorno Windows, algunos de ellos ya disponibles en prototipo.

La Colección contiene imágenes digitalizadas a todo color de materiales artísticos del Centro de Arte Contemporáneo Reina Sofia, así como varias bases de datos con información referencial. Se encarga de la'edición Micronet.

Esta empresa anuncia también la publicación de tres títulos multimedia para los que está haciendo desarrollos específicos de software: El Palacio Real, El camino de Santiago y La máquina del tiempo. Lo que a nosotros nos parece más destacable es que con estos productos Micronet da un nuevo paso en sus actividades relacionadas con la información electrónica: como los datos han sido recopilados por la misma empresa, podemos decir que Micronet comienza a ser también desde ahora productor de bases de datos.

Por su parte BSI Multimedia, que ha sido la única empresa española a la que el programa Impact/Multimedia de la Comunidad Europea ha concedido la dirección de un proyecto, el European computer interactive multimedia aided tourist information system (Ecimatis), está poniendo a punto una aplicación sobre las diferentes regiones europeas, que contendrá información turístico-cultural-geográfica. Para 1994 está prevista la preparación de los dos primeros títulos, sobre Cataluña y el Algarve. 
La editorial Enciclopèdia Catalana prepara el Hiperdiccionari de la Llengua Catalana, que integrará en un CD-ROM varios diccionarios de la propia editorial: general, ortográfico, castellano-catalán e inglés-catalán. Sus planes son incorporar en futuras ediciones otros diccionarios: francés-catalán, etimológico, etc.

Edicinco trabaja en varios CD-ROMs. En los próximos meses publicará su propia colección de software educativo y otros materiales relacionados con el arte y la historia de la ciudad de Valencia. Estos últimos son proyectos realizados en colaboración con el Ayuntamiento.

El grupo Innova Multimedia está desarrollando Viaje por el espacio, El hombre de cristal, Enfermedades contagiosas y su prevención, El mundo de los minerales y Laboratorio asistido por ordenador. Control asistido por ordenador, cuatro proyectos soportados por el Programa de Electrónica e Informática Nacional III (Pein III).

En una línea similar de productos, se encuentran también dos CD-ROMs españoles dirigidos a los usuarios de sistemas Macintosh: uno ya publicado, Info Barcelona 92; y otros tres de los que sólo existe el anuncio, munCAT, la Enciclopedia Multimedia de Anatomía y el Museo de Navarra.

Info Barcelona 92 es un libro electrónico trilingüe sobre Barcelona y sus Juegos Olímpicos. Ha sido realizado por el equipo hyperAlia, con la colaboración del COOB'92 y del CDTI. El editor en este caso fue Apple. La programación se llevó a cabo haciendo uso de HyperTalk, incluyendo imágenes de vídeo digital.

El Institut d'Estadística de Catalunya prepara munCAT, proyecto de hiperdocumento en el que se han incluido datos de los padrones municipales de Cataluña. La impresión del primer disco piloto corrió a cargo de The Lagrange Group.

La Enciclopedia Multimedia de Anatomía es un proyecto que, con financiación del CDTI, se encargan de llevar a cabo el Aula de Informática Aplicada, el grupo de investigación Latco (Universidad de Córdoba) y el Departamento de Neurociencias (Universidad del País Vasco). El producto final que debe obtenerse es un disco educativo multimedia. El Aula de Informática Aplicada, colaborando con la Universidad del País Vasco, trabaja así mismo en el desarrollo de Museo de Navarra.

Esta creciente producción de materiales para entornos Windows y Mac, que en algunos casos ofrecen funciones más o menos multimedia, ha implicado un nuevo cambio en el panorama español de la edición del CD-ROM: la vuelta a los desarrollos propios. Las facilidades que para el personal informático ofrecen los sistemas Windows y Macintosh están favoreciendo, como se puede ver, la reactivación de la figura de aquella empresa editora de discos ópticos que prepara sus propios programas.

Pero no sólo se está realizando trabajo de programación para estos dos entornos gráficos de usuario. En los últimos dos años algunas empresas se han lanzado a editar productos CD-ROM que incorporan software propio para el entorno DOS tradicional. ¿Hasta qué punto se puede hablar de creación de software propio? Y, lo que es más importante aún, ¿tiene sentido hoy ponerse a hacer ese tipo de programación "doméstica»? Analizaremos cuatro casos muy distintos: Drug Data Report, Casa de América, Lex Nova y Microdoc.

Drug Data Report es el título que ha publicado la Editorial Prous. Es posible incluir este disco en el grupo de productos que incorporan desarrollos de software propio, haciendo la salvedad de que la gestión del material textual de la base de 
datos se lleva a cabo utilizando las librerías de funciones de la versión para desarrolladores del sistema Dataware (los demás módulos del programa se han preparado con otras herramientas de programación). La base de datos resultante incluye descripciones de compuestos químicos, acompañadas de información bibliográfica científica, todo en inglés. El software permite además presentar en pantalla imágenes de las correspondientes estructuras químicas.

A nuestro juicio el producto final es de gran calidad. La única duda que nos asalta es si la editorial podrá amortizar pronto la inversión tan fuerte que ha tenido que realizar en desarrollo. Esperamos que asi sea, pues es un producto español más que presentable para el mercado internacional. Por otra parte, la editorial catalana, que tiene por costumbre preparar sus publicaciones en lengua inglesa, lleva ya tiempo cosechando éxitos de alcance internacional. De hecho sus planes son lanzar una versión para Windows de Drug Data Report, denominada Trilogy, así como otros nuevos discos: uno que incluirá las bases de datos correspondientes a sus revistas Drugs of the Future y Drug News \& Perspectives y otro dedicado a metodologías para la investigación básica y clínica de medicamentos.

Los CD-ROMs Casa de América y Microdoc presentan cierta similitud entre sí, en lo que a trabajos de desarrollo se refiere. Se ha incluido en los discos una serie de imágenes digitalizadas. Para gestionarlas, unos sencillos programas. En el caso de Microdoc estamos ante una forma insólita de edición, pues a cada cliente se le entrega un CD-ROM impreso "a medida», con imágenes digitalizadas de páginas de la prensa, que se almacenan en el disco según cuál sea el perfil del usuario. En ambos casos se trata de productos que han requerido poco esfuerzo de desarrollo, al menos en comparación con otros CD-ROMs españoles. Con el tiempo veremos cuál es la aceptación que tienen. Recordemos, por otra parte, que el primero de ellos ha sido financiado con fondos públicos.

Un caso muy distinto es el de Lex Nova, un CD-ROM con la legislación fiscal vigente recopilada por la editorial del mismo nombre. Para la gestión de los datos, Logitec ha desarrollado un software de recuperación documental, al que denomina CD-base. Resulta asombroso que una empresa española de un tamaño no muy grande se atreva hoy a preparar su propio software de CD-ROM. El resultado es un interfaz no muy sofisticado y necesariamente limitado en sus funciones. De todas formas se trata de una solución más económica que la de pagar licencias a una multinacional del CD-ROM. Los usuarios tienen la última palabra.

Seric Informática, empresa de Reus, ha publicado un CD-ROM en el que se distribuye una selección de shareware americano. Antes de final de año espera poder presentar un disco de similares características, pero con programas desarrollados en España.

Acabando con la enumeración de productos, ya larga, debemos citar 500 años después y los «data discman».

Con la colección 500 años después estamos ante la primera vez que en España se editan discos interactivos de tecnología CD-I. Bajo la dirección de Sabini, empresa conocida en el mundo bibliotecario, contando con la colaboración de otras empresas, se ha preparado esta publicación, que ha recibido financiación de la Sociedad Estatal para el Quinto Centenario y de la Comisión Europea. El disco incluye textos, imágenes y sonidos. Tanto la voz como los textos están en cuatro idiomas. El presupuesto ha sido próximo a los ochocientos millones de pesetas. 
En cuanto a los CD-ROMs de tres pulgadas diseñados para los lectores portátiles de Sony, es Micronet también quien está encabezando la iniciativa editora. Entre la oferta que se ofrece o se prepara están: Cronologia de los descubrimientos de Isaac Asimov (Ariel), Todos los estudios y carreras (Planeta), Los cuidados maternales (Planeta), Diccionario financiero (Deusto), Diccionario inglés (Biblograf), Diccionario actual de la lengua española (Biblograf), Diccionario de sinónimos (Biblograf), Dicodi (Incresa), Documentación de Medios, Código civil (Aranzadi), etc. Aún es pronto para saber si el formato «data discman» tendrá suficiente aceptación.

\section{Conclusiones y perspectivas de futuro}

Haciendo un juego de palabras con el título de la novela de Delibes, podríamos decir que «la sombra del online es alargada». España es, en gran medida, un país sin online. Además de la escasa oferta y utilización del online, se acusa la falta de grandes distribuidores locales. Pues bien, en el caso del CD-ROM español, hay dos editores de cierto tamaño: Micronet y La Lèy. Micronet es la única empresa que en 1993 ha encargado la estampación de varias decenas de miles de discos CD-ROM. En cuanto al número de títulos y de copias, la distancia es muy grande entre ambas empresas. Pero es también bastante considerable la diferencia existente entre el segundo y tercer editor. De hecho resulta muy dificil determinar quién ocupa el tercer puesto en el ranking. Hay una gran cantidad de editores que publican sólo uno o dos títulos. Parece que en el mercado CD-ROM español en cierta forma se repite la historia de nuestro online.

En el caso de La Ley, su reciente adquisición por parte de la multinacional holandesa Wolters Kluwer puede suponer un nuevo capítulo en la ajetreada historia de la editorial. Durante los próximos meses podremos saber cuál será la nueva política de edición electrónica de la empresa. La principal pregunta que está en el aire es si la compañía se responsabilizará de la publicación de otros materiales textuales de las editoriales del grupo.

De todas formas, llama la atención en nuestro país el escaso protagonismo del mundo editorial dentro del mercado de la edición de CD-ROM. Hasta este año no ha habido una penetración decidida de los grandes grupos editoriales españoles. Quienes han estimulado la creación de nuevos productos han sido, en muchos casos, las empresas de informática. En diversas ocasiones se han trazado planes para editar en CD-ROM grandes enciclopedias españolas. Después de tantas promesas habrá que observar si por fin sale alguna al mercado.

Por otra parte, en estos últimos años tanto el mercado editorial como el informático evolucionan a nivel mundial hacia el monopolio, o al menos hacia el oligopolio. El software de Dataware y el de Online Computer Systems han entrado con fuerza en España. Cabe preguntarse si entrará el de Silverplatter, que últimamente está cambiando su política empresarial llegando a acuerdos con terceros. Los desarrollos de Micronet están manteniendo sus posiciones a pesar de los envites de las multinacionales. La carrera de la edición de CD-ROMs en España acaba de empezar, y todo apunta a que habrá mercado para muchos. Pero es dudoso que haya mercado para tantas empresas. Están surgiendo demasiados pequeños editores. 
En cualquier caso, hay que recordar que la evolución tecnológica está cambiando las "reglas del juego». Hasta ahora para explicar lo que era el mercado del CD-ROM había que incidir en su dimensión editorial, más que en sus especificidades informáticas. El CD-ROM es sobre todo - solíamos decir- un medio de edición. Pero con los actuales precios de los grabadores CD-ROM el proceso de mastering ha cambiado de dinámica. Hace tres años la metamorfosis se produjo en el premastering, para el que desde entonces no es necesario un hardware específico. Con los últimos acontecimientos, el CD-ROM se está convirtiendo en un elemento de la informática de cada día, no sólo desde la perspectiva de los usuarios finales sino también desde el punto de vista del editor. Hacer CD-ROMs es cada vez más fácil.

En lo que se refiere al CD-ROM como fenómeno de masas, es indudable que la invasión vendrá necesariamente por la línea de los productos multimedia. Estamos viendo cómo se están fabricando los primeros títulos en España. Pero lo de ahora es probablemente sólo el comienzo.

Ante la casi inexistente oferta multimedia española en CD-ROM, no sería extraño que en 1994 viéramos cómo alguna empresa extranjera elige nuestro país para hacer sus inversiones, con el fin de situarse con una posición comercial aventajada dentro de un mercado que aquí tiene poco pasado y, sin embargo, mucho futuro. 